\title{
Cannabis Use among Secondary School Students in Jamaica: Factors Associated with Age of Initiation
}

T Bernard, WD Abel, P Whitehorne-Smith, G Mitchell, E Thompson, K Lalwani, C Sewell, DC Oshi

\begin{abstract}
The aim of this study was to determine whether perception of risk and accessibility of cannabis predicted the age of initiation of cannabis use among Jamaican secondary school students. Data from a nationally representative sample were analysed. Descriptive statistical analysis was done while binary logistic regression was used to compute point estimates and confidence intervals (CIs). The median age of initiation was 13 years. Gender was a predictor of age of initiation, with females having 39\% less risk of initiating cannabis use at the age of 13 years or younger before adjusting for covariates (crude odds ratio [COR]: 0.61; 95\% CI: 0.48, 0.77), which increased to $42 \%$ reduced risk of initiating cannabis use at the age of 13 years or younger after adjusting for covariates (adjusted OR [AOR]: 0.58; 95\% CI: 0.39, 0.85). There was a significant inverse association between grade level in school and age of initiation of cannabis use, with $11^{\text {th }}$ grade students having a significantly reduced risk of commencing cannabis use at the age of 13 years or younger (COR: 0.41; 95\% CI: 0.23, 0.70; AOR: 0.41; 95\% CI: 0.23, 0.72). Participants who perceived cannabis use as moderately harmful were $67 \%$ less likely to initiate cannabis use at the age of 13 years or younger compared to participants who thought it was not harmful (AOR: 0.33; 95\% CI: 0.12, 0.88). Perceptions of access to cannabis did not predict age of initiation of cannabis use. Being female, being in the $11^{\text {th }}$ grade and the perception that cannabis use was moderately harmful significantly reduced the risk of initiating cannabis use at the age of 13 years or younger.
\end{abstract}

Keywords: Accessibility to cannabis, age of initiation, cannabis, cannabis use, Jamaica, risk perception

\section{EI Uso de Cannabis entre los Estudiantes de Secundaria en Jamaica: Factores Asociados con la Edad de Iniciación}

T Bernard, WD Abel, P Whitehorne-Smith, G Mitchell, E Thompson, K Lalwani, C Sewell, DC Oshi

\begin{abstract}
RESUMEN
El objetivo de este estudio fue determinar si la percepción del riesgo y la accesibilidad al cannabis predecian la edad de iniciación del uso de cannabis entre los estudiantes de escuela secundaria en Jamaica. Se analizaron los datos de una muestra nacionalmente representativa. Se realizó un análisis estadístico descriptivo, y se utilizó una regresión logística binaria para computar las estimaciones puntuales y los intervalos de confianza (IC). La edad promedio de iniciación fue de 13 años. El género fue un predictor de la edad de iniciación, presentando las hembras un riesgo 39\% menor de iniciar el uso de cannabis a la edad de 13 años o más joven,
\end{abstract}

From: Department of Community Health and Psychiatry, The University of the West Indies, Mona, Jamaica, West Indies.
Correspondence: Dr T Bernard, Kingston Public Hospital, North Street, Kingston, Jamaica, West Indies. Email: houseofterrence@, gmail.com 
antes del ajuste de las covariables (odds ratio crudo [COR]: 0.61; 95\% IC: 0.48, 0.77), que aumentó a 42\% el riesgo reducido de iniciar el uso de cannabis a la edad de 13 años o más joven después del ajuste de las covariables (OR ajustado [AOR]: 0.58; 95\% IC: 0.39, 0.85). Hubo una asociación inversa significativa entre el nivel del grado en la escuela y la edad de la iniciación en el uso de cannabis, presentando los estudiantes de $11^{\circ}$ grado un riesgo significativamente reducido de comenzar el uso de cannabis a la edad de 13 años o menos (COR: 0.41; 95\% IC: 0.23, 0.70; AOR: 0.41; 95\% IC: 0.23, 0.72). Los participantes que percibian el consumo de cannabis como moderadamente dañino presentaban una probabilidad $67 \%$ menor de iniciarse en el uso de cannabis a la edad de 13 años o menos, en comparación con los participantes que pensaban que no era perjudicial (AOR: 0.33; 95\% IC: 0.12, 0.88). Las percepciones de acceso al cannabis no predecían la edad de iniciación en el uso del cannabis. El ser mujer, el estar en $11^{\circ}$ grado, y la percepción de que el consumo de cannabis era moderadamente dañino, reducían significativamente el riesgo de iniciación en el uso de cannabis a la edad de 13 años o más joven.

Palabras clave: Accesibilidad al cannabis, edad de iniciación, cannabis, consumo de cannabis, Jamaica, percepción del riesgo

West Indian Med J 2017; 66 (5): 547

\section{INTRODUCTION}

Cannabis remains the most widely used illicit substance globally, especially among young persons. Data assessing chronic use of cannabis were collected from the secondary school population of Canada and the United States of America (USA) in 2010-11 and 2014, respectively. Measured by past-year prevalence (chronic use), $8^{\text {th }}, 10^{\text {th }}$ and $12^{\text {th }}$ graders were surveyed, revealing that approximately 24\% (Canada) and 23\% (USA) were chronic users of cannabis (1). These figures were challenged by the Latin American country of Chile, which had a prevalence rate of $30.6 \%$ in 2013 (1). Chronic use in Chile has been on a steady increase since 2003 when it was $13 \%$. The most recent Chilean data represented an $11.1 \%$ increase from the 2011 data which reported chronic use to be at $19.5 \%$ (1). On the contrary, data from Peru indicated that chronic use had been stable for the period 2005-12, while past-year prevalence in 2012 was $2.2 \%$, a $0.6 \%$ decrease from 2005 (1).

In the age group of 12-17 years, the lifetime prevalence and past-year (chronic) prevalence of cannabis use in Canada were $21.60 \%$ and $14.80 \%$, respectively, while those in the USA were $16.44 \%$ and $13.44 \%$, respectively. According to Chilean 2012 data, the prevalence of lifetime and chronic cannabis use was $7.48 \%$ and $5.18 \%$, respectively. Peru remained the Latin American country with the lowest rate of cannabis use, with a lifetime prevalence of $2.23 \%$ and chronic use of $1.94 \%$ in 2010 , while the prevalence among secondary school students in the USA and Venezuela was $13.80 \%$ and $0.60 \%$, respectively, in 2009 for current (past month) consumption (1-4).

Within the Caribbean region, the prevalence of cannabis use among secondary school students ranged from $3.29 \%$ in Suriname to $17.47 \%$ in Dominica. The annual prevalence of cannabis use in Jamaica (12.4\%) was above the average annual prevalence for the Caribbean [9.76\%] (2).

Early initiation among adolescents is of public health concern as cannabis use is associated with a range of negative health and psycho-social effects, including increased risk of addiction and increased risk of anxiety and depression $(5,6)$. It is also linked with psychosis, especially among people with a pre-existing genetic vulnerability (7). It has also been associated with impaired motor coordination, impairment of critical cognitive functions, increased risk of chronic bronchitis, increased risk of respiratory infections and cardiovascular conditions including myocardial infarction, stroke and transient ischaemic attacks (7). There is also evidence suggesting a positive association of early initiation of cannabis use with adverse social and economic outcomes, poor grades at school, lower income, unemployment, greater need for social support (8-10).

Despite these effects of early onset of cannabis use, evidence suggests that young persons still initiate cannabis use at relatively young ages. The age of initiation for Caribbean secondary school students ranged from 12.53 
years in St Kitts and Nevis to 14.41 years in Suriname. Meanwhile, Jamaica's age of initiation (12.9 years) fell below the Caribbean average of 13.01 years (3).

Numerous factors often influence the initiation of drug use (11-17). Researchers have well noted that sociodemographic factors such as social disadvantage, neighbourhood of residence, gender and socio-economic status play a significant role in the onset of use (11-13, 16). Parental involvement and relationship, school factors (such as academic achievement, attendance and belongingness), as well as accessibility and perception of risk have all been found to be associated with the initiation of cannabis use (18-20).

The present study sought to explore how perception of risk, access and availability of substances were related to the age of initiation of cannabis use within the Jamaican secondary school population.

\section{SUBJECTS AND METHODS}

This study was a cross-sectional survey of 3365 participants from 38 public and private secondary schools in Jamaica. It was conducted by the National Council on Drug Abuse (NCDA) in Jamaica, with technical support and funding from the Organization of American States' Inter-American Drug Abuse Control Commission (CICAD) in the USA.

The population studied was all secondary school students in Jamaica. A stratified random sample was taken which resulted in the selection of second, fourth and sixth forms from the selected schools.

All participants completed a self-administered questionnaire: the Inter-American Uniform Drug Use Data System (SIDUC), a standardized questionnaire developed by the CICAD. The NCDA received permission to conduct the study from the principals, the Ministry of Education and the Ministry of Health. Ethical approval was obtained from The University Hospital of the West Indies/The University of the West Indies, Mona, Faculty of Medical Sciences Ethics Committee. Parents signed consent forms and students filled out assent forms prior to data collection. Confidentiality and anonymity were assured. The students were given a list of professionals from whom they could receive assistance if they experienced any distress during the process.

PSPP software (GNU Project) was used to analyse the data. The age of initiation was transformed into a binary variable $(<13$ years and $>13$ years). Descriptive analysis was used to compute proportion (frequencies and percentages) of sociodemographic variables, risk perception and access to cannabis as well as age of initiation of cannabis use among the participants. Bivariate analysis was done to assess the sociodemographic, risk perception and access to cannabis factors in relation to the age of initiation of cannabis use. Binary logistic regression was used to assess the association between the independent variables and age of initiation of cannabis use.

\section{RESULTS}

Females accounted for approximately $57 \%$ of the 3365 participants. The mean age of all participants was 14.97 years (standard deviation: 1.71 years). Among all participants, the mean age of initiation of cannabis use was 13.0 years (range: 5-19 years), while disaggregated, it was 13 years (range: 5-19 years) and 14 years (range: 5-17 years) for males and females, respectively. A total of 684 participants $(20.3 \%)$ reported lifetime use of cannabis. Among the participants who reported lifetime use, $381(43.7 \%)$ had used cannabis over the past one year, while $208(47.1 \%)$ indicated they had used cannabis in the past one month (current use).

The highest proportion of participants was in eighth grade $(30.8 \%)$. A large proportion $(64.3 \%)$ of the participants considered frequent smoking of cannabis to be very harmful, while $10.1 \%$ perceived it to be moderately harmful. On the contrary, only $4.7 \%$ considered it not harmful. Regarding access to cannabis, $41.5 \%$ of the participants stated that it would be easy for them to get cannabis, compared to $12.3 \%$ who opined that it would be hard. As many as $26.2 \%$ did not know how easy or hard it would be for them to get the substance (Table 1).

Table 2 shows the results of bivariate analysis of key sociodemographic, risk perception and access characteristics of the study participants in relation to the age of initiation of cannabis use. The median age of initiation of cannabis was 13.0 years (range: 5-19 years). Predicated on the median age of initiation (13.0 years), age of initiation was stratified into two: at 13 years or younger $(\leq 13$ years) versus after 13 years ( $>13$ years). By gender, males constituted $54.2 \%$ of the participants who initiated cannabis use at the age of 13 years or younger. Females accounted for $45.2 \%$ of participants who initiated cannabis use at the age of 13 years or younger, but $56.0 \%$ of those who initiated use after the age of 13 years.

All the eighth grade participants who initiated cannabis use did so before or at the age of 13 years and accounted for $26.1 \%$ of those who initiated use at the age of 13 years or younger. The least proportion of those who started cannabis use at the age of 13 years or younger was $7.9 \%\left(12^{\text {th }}\right.$ grade), while the highest proportion 
Table 1: Sociodemographic, risk perception and access characteristics of the study participants, Jamaica, $2013(n=3365)$

\begin{tabular}{ll}
\hline Characteristics & n (\%) \\
\hline Gender* & $1426(42.4)$ \\
Male & $1915(56.9)$ \\
Female & $14.97,1.71$ \\
Age (mean, standard deviation) & \\
Grade level & $1037(30.8)$ \\
$8^{\text {th }}$ grade & $1109(33.0)$ \\
$10^{\text {th }}$ grade & $888(26.4)$ \\
$11^{\text {th }}$ grade & $331(9.8)$ \\
12 $2^{\text {th }}$ grade & \\
Type of school & $3295(97.9)$ \\
Public & $70(2.1)$ \\
Private & \\
Risk perception* & $158(4.7)$ \\
Not harmful & $208(6.2)$ \\
Slightly harmful & $339(10.1)$ \\
Moderately harmful & $2162(64.3)$ \\
Very harmful & $328(9.8)$ \\
Don't know & \\
Access to cannabis* & $1396(41.5)$ \\
Easy to get & $413(12.3)$ \\
Hard to get & $538(16.0)$ \\
Dnable to get & $882(26.2)$ \\
\hline &
\end{tabular}

* Missing data: gender (24 participants, $0.61 \%$ ), risk perception (170 participants, $5.05 \%$ ) and access to cannabis (136 participants, $4.04 \%$ ).

$(38.8 \%)$ was among $10^{\text {th }}$ graders. Regarding risk perception, $13 \%$ of participants who initiated cannabis use at the age of 13 years or younger felt it was not harmful, compared to $10.8 \%$ of those who initiated its use after the age of 13 years. A total of $50 \%$ of participants who started using cannabis at the age of 13 years or younger perceived it to be very harmful, compared to $48.8 \%$ of those who initiated its use after the age of 13 years. Most participants $(80.9 \%)$ who started using cannabis before or at 13 years of age reported it would be easy for them to get cannabis, and this was also the perception of $85.6 \%$ of participants who initiated cannabis use after the age of 13 years.

Table 3 displays the results of logistic regression analysis of the factors associated with age of initiation of cannabis use among the study participants. Gender was a predictor of initiation of cannabis use at the age of 13 years or younger. In the logistic regression model before adjustment for covariates (ie grade level of the students and type of school, perception of risk and access to
Table 2: Sociodemographic, risk perception and access characteristics in relation to age of initiation of cannabis use of the study participants, Jamaica, $2013(\mathrm{n}=3365)$

\begin{tabular}{|c|c|c|c|}
\hline \multirow[b]{2}{*}{ Characteristics } & \multirow[b]{2}{*}{$\begin{array}{c}\text { All participants: } \\
\text { n (\%) }\end{array}$} & \multicolumn{2}{|c|}{$\begin{array}{l}\text { Age of initiation } \\
\text { of cannabis use }\end{array}$} \\
\hline & & $\begin{array}{c}\leq 13 \text { years } \\
(\%)\end{array}$ & $\begin{array}{c}>13 \text { years } \\
(\%)\end{array}$ \\
\hline Total & 3365 & 330 & 250 \\
\hline \multicolumn{4}{|l|}{ Gender* } \\
\hline Male & $1426(42.4)$ & 54.2 & 43.6 \\
\hline Female & $1915(56.9)$ & 45.2 & 56.0 \\
\hline \multicolumn{4}{|l|}{ Grade level } \\
\hline $8^{\text {th }}$ grade & $1037(30.8)$ & 26.1 & 0.0 \\
\hline $10^{\text {th }}$ grade & $1109(33.0)$ & 38.8 & 36.8 \\
\hline $11^{\text {th }}$ grade & $888(26.4)$ & 27.3 & 44.8 \\
\hline $12^{\text {th }}$ grade & $331(9.8)$ & 7.9 & 18.4 \\
\hline \multicolumn{4}{|l|}{ Type of school } \\
\hline Public & 3295 (97.9) & 97.9 & 96 \\
\hline Private & $70(2.1)$ & 2.1 & 4.0 \\
\hline \multicolumn{4}{|l|}{ Risk perception* } \\
\hline Not harmful & $158(4.7)$ & 13.0 & 10.8 \\
\hline Slightly harmful & $208(6.2)$ & 13.3 & 11.6 \\
\hline Moderately harmful & $339(10.1)$ & 14.2 & 20.8 \\
\hline Very harmful & $2162(64.3)$ & 50 & 48.8 \\
\hline Don’t know & $328(9.8)$ & 4.9 & 6.4 \\
\hline \multicolumn{4}{|l|}{ Access to cannabis* } \\
\hline Easy to get & $1396(41.5)$ & 80.9 & 85.6 \\
\hline Hard to get & $413(12.3)$ & 7.3 & 4.8 \\
\hline Unable to get & $538(16.0)$ & 3.3 & 2.4 \\
\hline Don’t know & $882(26.2)$ & 6.7 & 5.2 \\
\hline
\end{tabular}

* Missing data: gender (24 participants, $0.61 \%$ ), risk perception (170 participants, $5.05 \%$ ) and access to cannabis (136 participants, $4.04 \%$ ).

Percentages may not add up to 100 due to rounding.

cannabis), females had 39\% less risk of initiating cannabis use at the age of 13 years or younger compared to males (crude odds ratio [COR]: 0.61; 95\% confidence interval [CI]: 0.48, 0.77).

In the fully adjusted regression model, the association between gender and age of initiation of cannabis use remained significant as females had $42 \%$ less risk of initiating cannabis use before or at 13 years of age compared to males (adjusted odds ratio [AOR]: 0.58; $95 \%$ CI: $0.39,0.85)$. There was also a significant association between grade level of the participants and age of initiation of cannabis use. However, out of the four grade levels $\left(8^{\text {th }}, 10^{\text {th }}, 11^{\text {th }}\right.$ and $\left.12^{\text {th }}\right)$, only the $11^{\text {th }}$ grade was a predictor of age of initiation of cannabis use. Participants in the $11^{\text {th }}$ grade had a significantly reduced risk of initiation of cannabis use at the age of 
Table 3: Factors associated with early age of initiation of cannabis use of the study participants, Jamaica, 2013

\begin{tabular}{|c|c|c|c|c|c|}
\hline Characteristics & $\begin{array}{c}\leq 13 \text { years } \\
\text { n }(\%)\end{array}$ & $\begin{array}{l}>13 \text { years } \\
\text { n }(\%)\end{array}$ & $\begin{array}{l}\text { Crude odds ratio } \\
\text { ( } 95 \% \text { confidence interval) }\end{array}$ & $\begin{array}{l}\text { Adjusted odds ratio } \\
\text { (95\% confidence interval) }\end{array}$ & Adjusted $p$-value \\
\hline \multicolumn{6}{|l|}{ Gender } \\
\hline Male & $179(54.2)$ & $109(43.6)$ & 1 (reference) & 1 (reference) & \\
\hline Female & $149(45.2)$ & $140(56.0)$ & $0.61(0.48,0.77)$ & $0.58(0.39,0.85)$ & 0.00 \\
\hline \multicolumn{6}{|l|}{ Grade level } \\
\hline $8^{\text {th }}$ grade & $86(26.1)$ & $0(0.0)$ & 1 (reference) & 1 (reference) & \\
\hline $10^{\text {th }}$ grade & $128(38.8)$ & $92(36.8)$ & - & - & - \\
\hline $11^{\text {th }}$ grade & $90(27.3)$ & $112(44.8)$ & $0.41(0.23,0.70)$ & $0.41(0.23,0.72)$ & 0.00 \\
\hline $12^{\text {th }}$ grade & $26(7.9)$ & $46(18.4)$ & $0.70(0.40,1.23)$ & $0.80(0.45,1.44)$ & 0.46 \\
\hline \multicolumn{6}{|l|}{ Type of school } \\
\hline Public & $323(97.9)$ & $240(96.0)$ & 1 (reference) & 1 (reference) & \\
\hline Private & $7(2.1)$ & $10(4.0)$ & $0.52(0.20,1.39)$ & $0.42(0.14,1.28)$ & 0.13 \\
\hline \multicolumn{6}{|l|}{ Risk perception } \\
\hline Not harmful & $43(13.0)$ & $27(10.8)$ & 1 (reference) & 1 (reference) & \\
\hline Slightly harmful & $44(13.3)$ & $29(11.6)$ & $0.63(0.27,1.46)$ & $0.39(0.15,1.06)$ & 0.06 \\
\hline Moderately harmful & $47(14.2)$ & $52(20.8)$ & $0.66(0.29,1.52)$ & $0.33(0.12,0.88)$ & 0.03 \\
\hline Very harmful & $164(50.0)$ & $122(48.8)$ & $1.11(0.50,2.46)$ & $0.67(0.26,1.71)$ & 0.4 \\
\hline Don't know & $16(4.9)$ & $16(6.4)$ & $0.74(0.36,1.55)$ & $0.46(0.19,1.09)$ & 0.08 \\
\hline \multicolumn{6}{|l|}{ Access to cannabis } \\
\hline Easy to get & $267(80.9)$ & $214(85.6)$ & 1 (reference) & 1 (reference) & \\
\hline Hard to get & $24(7.3)$ & $12(4.8)$ & $1.36(0.67,2.76)$ & $1.24(0.55,2.76)$ & 0.60 \\
\hline Unable to get & $11(3.3)$ & $6(2.4)$ & $0.85(0.32,2.24)$ & $1.29(0.44,4.14)$ & 0.67 \\
\hline Don't know & $22(6.7)$ & $13(5.2)$ & $0.92(0.28,3.09)$ & $1.53(0.35,6.45)$ & 0.58 \\
\hline
\end{tabular}

Percentages may not add up to 100 due to rounding.

13 years or younger (COR: $0.41 ; 95 \% \mathrm{CI}: 0.23,0.70)$. This association remained significant after adjusting for sociodemographic and other factors (AOR: 0.41; 95\% CI: $0.23,0.72$ ). There was no significant association between type of school and age of initiation of cannabis use.

As also shown in Table 3, in the unadjusted logistic regression model, the perception that frequent cannabis use was moderately harmful showed no association with the age of initiation (COR: 0.66; 95\% CI: 0.29, 1.52). However, when all other factors were adjusted for, it showed a strong inverse association with the age of initiation of cannabis use. Participants who perceived cannabis use to be moderately harmful were $66 \%$ less likely to initiate cannabis at 13 years of age or younger compared to participants who thought it was not harmful (AOR: $0.33 ; 95 \% \mathrm{CI}: 0.12,0.88$ ). This strong protective effect was, interestingly, not observed for the perception that cannabis use was very harmful (COR: $1.11 ; 95 \% \mathrm{CI}$ : 0.50, 2.46; AOR: 0.67 ; 95\% CI: $0.26,1.71)$. Access to cannabis was not found to have a significant association with age of initiation of cannabis use.

\section{DISCUSSION}

The findings of the study revealed that $20.30 \%$ of the students reported lifetime use of cannabis which is approximately equivalent to one in five students having used cannabis. This was a marginal decrease from the reported lifetime use of cannabis among students in Jamaica in $2010(21.56 \%$ vs $20.30 \%)$. It is higher than the past-year use of $16.5 \%$ among Canadian secondary school students in 2013-14 (4) and eighth grade students in the USA (12.7\%), but very much lower than the $41.8 \%$ among USA students in 2013.

The median age of initiation of cannabis use was 13 years, thus reflecting a slight increase from previous data which reported 12.90 years among students in Jamaica (3).

A slightly higher proportion (50\%) of students who were 13 years of age or younger perceived frequent cannabis use to be very harmful, compared to $48.8 \%$ of students who were older than 13 years. It is reasonable to surmise that students' perception of the harmfulness of cannabis was based on information acquired from a variety of sources, including radio, community members 
and schools. However, data on sources of information on drugs were not collected in this study. Alhyas et al found that students used a variety of sources to acquire information about drugs and the risks involved in using them (21). However, schools was not named as a key source, and students had misinformation about drugs and their harmfulness from other sources.

Students' perception that cannabis use was moderately harmful was not a predictor of early age of initiation when covariates were not adjusted for. However, when the covariates were adjusted for, students who perceived cannabis use to be moderately harmful were $66 \%$ less likely to initiate its use at the age of 13 years or younger compared to those who thought it was not harmful. It is not surprising that young persons who deemed cannabis harmful would refrain from commencing its use (22). Ordinarily, perception of cannabis as being moderately harmful would be taken as an apprehension that would translate into avoiding cannabis. Interestingly, perception of cannabis as being very harmful did not reduce the risk of commencing its use at the age of 13 years or younger.

The reasons were not clear. However, firstly, it could be that social forces within the environment (household, community, school) soon overcame the apprehension to abstain from cannabis use. As Malmberg et al has noted, approval of cannabis use by one's social environment (which could include immediate household/family members, including parents, and peer pressure from friends and schoolmates) constitutes a risk factor for early initiation of cannabis use (22). Secondly, generally, knowledge does not always translate into appropriate behaviour, and so being aware of the harmful effects of cannabis may not be enough per se to prevent young persons from initiating its use. Thirdly, misinformation about cannabis among the youth might counter social discourses that attempt to provide proper information on the substance to the young persons.

The results of the present study found that a significant number of participants believed that accessing cannabis was 'easy' $(41.5 \%)$, while a much smaller number reported it being 'hard' $(12.3 \%)$. In the bivariate analysis, an inverse relationship between age of initiation and access to cannabis was observed. Specifically, as age of initiation decreased, the perception of difficulty in accessing drugs increased. This finding is consistent with those reported by researchers elsewhere who pointed out that perception of access to drugs is affected by adolescent age which influences how likely they will be able to source drugs regularly (23). Furthermore, persons who perceived that licit and illicit drugs were readily available and who had the perception that cannabis was easy to access might be more likely to try using it. Interestingly, however, in the logistic model, perception of access to cannabis was neither a risk nor protective factor for initiation at the age of 13 years or younger. Perhaps, some social factors within the society which were not explored in this study exerted more powerful influences on when cannabis was initiated than perception of access did $(20,22,24,25)$.

The study finding that gender was a predictor of early age of initiation of cannabis use is not entirely surprising. As in many other societies, males in the Jamaican society are socialized in ways that encourage undertaking some social actions earlier than females, eg use of drugs. This finding is thus consistent with reports from the literature $(11,24)$ which highlight a gender disparity in relation to cannabis consumption, inferring that males had a greater risk of cannabis use.

The data were based on an observational study using a self-administered questionnaire, which had the usual limitations such as recall bias and giving responses thought to be socially acceptable.

\section{CONCLUSION}

Perception that cannabis was moderately harmful was a protective factor with students who held this belief being $66 \%$ less likely to initiate cannabis use at the age of 13 years or younger. Other protective factors were being a female and being in the $11^{\text {th }}$ grade at school. Perception that cannabis was very harmful as well as perception of access were not predictors of age of initiation of cannabis use.

More research is needed to understand further the reasons why the protective factors found in this study reduced the risk of initiation of cannabis use at the age of 13 years or younger. Programmes aimed at addressing cannabis use among students need to take these into consideration in designing and implementing their activities.

\section{ACKNOWLEDGEMENTS}

The authors wish to thank the NCDA and the CICAD's Inter-American Observatory on Drugs.

\section{AUTHORS' NOTE}

The authors declare that they have no conflict of interest.

\section{REFERENCES}

1. Inter-American Drug Abuse Control Commission (CICAD), Secretariat for Multidimensional Security (SMS), Organization of American States 
(OAS). Report on drug use in the Americas, 2015. Washington, DC: CICAD, SMS, OAS; 2015. Available from: http://www.cicad.oas.org/ oid/pubs/DrugUseAmericas_ENG_web.pdf.

2. Inter-American Drug Abuse Control Commission (CICAD), Secretariat for Multidimensional Security (SMS), Organization of American States (OAS). Report on drug use in the Americas, 2011. Washington, DC: CICAD, SMS, OAS; 2011. Available from: http://www.cicad.oas.org/ oid/pubs/DrugUse_in_Americas_2011_en.pdf.

3. Inter-American Drug A buse Control Commission (CICAD), Secretariat for Multidimensional Security (SMS), Organization of American States (OAS). Comparative analysis of student drug use in Caribbean countries: Antigua and Barbuda, Barbados, Dominica, Grenada, Guyana, Haiti, Jamaica, St Kitts and Nevis, St Lucia, St Vincent and the Grenadines, Trinidad and Tobago and Suriname. A report on student drug use in 12 Caribbean countries. Washington, DC: CICAD, SMS, OAS; 2010. Available from: http://www.cicad.oas.org/Main/pubs/StudentDrugUseCaribbean2011.pdf.

4. Canadian Centre on Substance Use and Addiction. Canadian Drug Summary, August 2017. Accessed August 6, 2017. Available from: http://www.ccsa.ca/Resource\%20Library/CCSA-Canadian-DrugSummary-Cannabis-2017-en.pdf.

5. Volkow ND, Baler RD, Compton WM, Weiss SRB. Adverse health effects of marijuana use. N Engl J Med 2014; 370: 2219-27.

6. Schweinsburg AD, Brown SA, Tapert SF. The influence of marijuana use on neurocognitive functioning in adolescents. Curr Drug Abuse Rev 2008; 1: 99-111.

7. Fergusson DM, Horwood LJ. Early onset cannabis use and psychosocial adjustment in young adults. Addiction 1997; 92: 279-96.

8. Bohnert KM, Anthony JC, Breslau N. Parental monitoring at age 11 and subsequent onset of cannabis use up to age 17: results from a prospective study. J Stud Alcohol Drugs 2012; 73: 173-7.

9. Mann A. Relationships matter: impact of parental, peer factors on teen, young adult substance abuse. NIDA Notes 2003; 18. Available from: https://archives.drugabuse.gov/NIDA_Notes/NNVol18N2/ Relationships.html.

10. Kuntsche E, Jordon MD. Adolescent alcohol and cannabis use in relation to peer and school factors: results of multilevel analyses. Drug Alcohol Depend 2006; 84: 167-74.

11. Tu AW, Ratner PA, Johnson JL. Gender differences in the correlates of adolescents' cannabis use. Subst Use Misuse 2008; 43: 1438-63.

12. Henry KL, Thornberry TP, Huizinga DH. A discrete-time survival analysis of the relationship between truancy and the onset of marijuana use. $\mathrm{J}$ Stud Alcohol Drugs 2009; 70: 5-15.
13. Guo J, Hill KG, Hawkins JD, Catalano RF, Abbott RD. A developmental analysis of sociodemographic, family, and peer effects on adolescent illicit drug initiation. J Am Acad Child Adolesc Psychiatry 2002; 41: $838-45$.

14. Brook JS, Lukoff IF, Whiteman M. Initiation into adolescent marijuana use. J Genet Psychol 1980; 137: 133-42.

15. Derzon JH. Using correlational evidence to select youth for prevention programming. J Prim Prev 2007; 28: 421-47.

16. King K, Hoffman AR. Sex and grade level differences in marijuana use among youth. J Drug Educ 2012; 42: 361-77.

17. Tonin SL, Burrow-Sanchez JJ, Harrison RS, Kircher JC. The influence of attitudes, acculturation and gender on substance use for Mexican American middle school students. Addict Behav 2008; 33: 949-54.

18. Keyes KM, Shculenberg JE, O'Malley PM, Johnston LD, Bachman JG, $\mathrm{Li} \mathrm{G}$ et al. The social norms of birth cohorts and adolescent marijuana use in the United States, 1976-2007. Addiction 2011; 106: 1790-1800.

19. Hayaki J, Hagerty CE, Herman DS, de Dios MA, Anderson BJ, Stein MD. Expectancies and marijuana use frequency and severity among young females. Addict Behav 2010; 35: 995-1000.

20. Collins D, Abadi MH, Johnson K, Shamblen S, Thompson K. Nonmedical use of prescription drugs among youth in an Appalachian population: prevalence, predictors and implications for prevention. $\mathrm{J}$ Drug Educ 2011; 41: 309-26.

21. Alhyas L, Al Ozaibi N, Elarabi H, El-Kashef A, Wanigaratne S, Almarzouqi A et al. Adolescents' perception of substance use and factors influencing its use: a qualitative study in Abu Dhabi. JRSM Open 2015; 6: 2054270414567167.

22. Malmberg M, Overbeek G, Vermulst AA, Monshouwer K, Vollebergh WAM, Engels RCME. The theory of planned behavior: precursors of marijuana use in early adolescence? Drug Alcohol Depend. 2012; 123: $22-8$.

23. Johnston LD, O’Malley PM, Bachman JG, Schulenberg JE, Miech RA. Monitoring the future. National survey results on drug use, 1975-2013. Volume 1: secondary school students. Ann Arbor, Michigan: Institute for Social Research, The University of Michigan; 2014.

24. Guxens M, Nebot M, Ariza C, Ochoa D. Factors associated with the onset of cannabis use: a systematic review of cohort studies. Gaceta Sanitaria 2007; 21: 252-60.

25. Schmits E, Mathys C, Quertemont E. A longitudinal study of cannabis use initiation among high school students: effects of social anxiety, expectancies, peers and alcohol. J Adolesc 2015; 41: 43-52. 